\title{
Reverse Electrodialysis Energy Harvesting System Using High-Gain Step-Up DC/DC Converter
}

\author{
Ying Huang, Student Member, IEEE, Ying Mei, Song Xiong, Member, IEEE, Siew-Chong Tan, Senior \\ Member, IEEE, Chuyang Y. Tang and Shu Yuen (Ron) Hui, Fellow, IEEE
}

\begin{abstract}
Salinity gradient power (SGP) between fresh river water and sea water is a form of renewable energy with huge potential but not well explored. This paper presents a feasibility study on energy harvesting of SGP based on (i) the use of reverse electrodialysis (RED) stack and (ii) the combined use of harmonics-boosted resonant inverter and multistage diodecapacitor step-up converter. The properties of an RED stack have been characterized into steady-state $\mathrm{AC}$ and DC equivalent circuit models for power converter design for the first time. The gains of the resonant inverter and diode-capacitor step-up converter are also optimized for maximizing the energy efficiency. An RED stack prototype comprising multiple alternating anion and cation exchange membranes with an area of $0.01 \mathrm{~m}^{2}$ each has been constructed. The DC output voltage of $2 \mathrm{~V}-3 \mathrm{~V}$ from the RED stack has been stepped up to be over $155 \mathrm{~V}$. This study has confirmed that energy can be harvested with a membrane power density of at least $1.4 \mathrm{~W} / \mathrm{m}^{2}$, a power converter's efficiency exceeding $85 \%$ and a voltage gain of 67.3 times.
\end{abstract}

Index Terms-Salinity gradient power, reverse electrodialysis, high-gain step-up DC/DC converter, equivalent circuit model.

\section{INTRODUCTION}

Apart from hydropower, the annual global fresh water discharged of approximately $37300 \mathrm{~km}^{3}$ represents another huge source of clean energy that can be harnessed, in the form of salinity gradient power (SGP) [1]. The process of harvesting SGP is achieved through the extraction of electrical power resulted from the controlled mixing of water streams of different salinity in a membrane reactor [2]. Theoretically, approximately $2.3 \mathrm{MW}$ of salination power can be captured for useful work when river water flows at $1 \mathrm{~m}^{3} /$ second into the sea [2]-[4]. Around 2.4-2.6 TW can be harnessed globally when average discharges of all river water are taken into consideration [2]-[4]. Furthermore, a broad range of water sources, including high salinity water streams from the desalination plant, treated waste water effluent, and industrial cooling water, can be added into this energy source [4]. An important technology for extracting the SGP is the reverse electrodialysis (RED) stack, which is shown in Fig. 1. In an RED stack, a specific number of cation exchange membranes (CEM) and anion exchange membranes (AEM) are alternatively piled, forming the concentrated solution compartments and dilute solution compartments [2]. Positively charged ions and negatively charged ions are transported selectively through the ion exchange membranes in opposing directions [5]. In this process, an electrical potential is established from the chemical potential, and is then converted to electricity through the redox reactions on the electrodes [6].

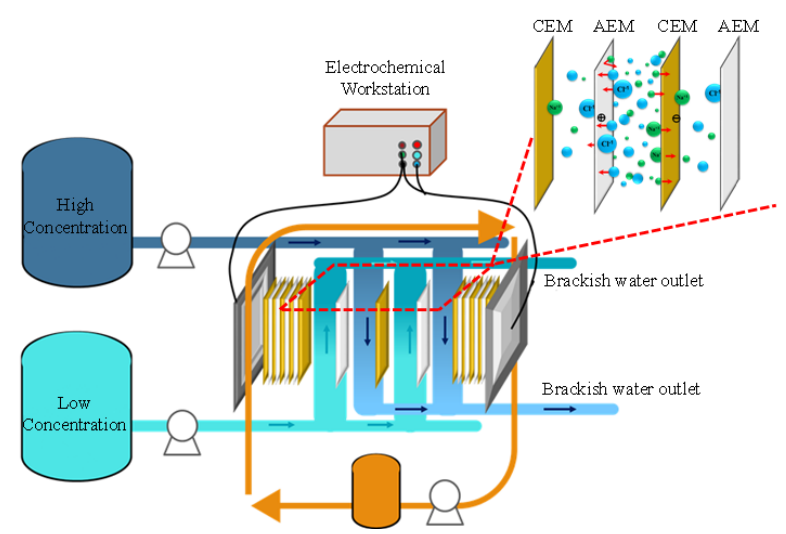

Fig. 1. Figure of an RED stack experimental setup.

For the RED stack, the electricity produced is of DC power form and exists at a relatively low level (normally from a few volts to a few tens of volts). For the plant pilot-scale RED stack reported in [7] and [8], the output voltage are around $6 \mathrm{~V}$ and $20 \mathrm{~V}$. For a smaller-scale implementation or that of the laboratory-scale, the output voltage is much lower. Up to now, the optimal output voltage of the RED stack has not been determined. To harvest the energy from the RED stack to feed an AC grid or the pump driver system of the plant, a front-end high-gain step-up DC/DC converter is required. Various types of topologies have been proposed as potential means of high step-up DC/DC converters [9]-[18]. For transformer-based or coupled-inductor-based converters, high voltage gain of the converter can be easily achieved by adopting large turns ratio [10], [11]. For applications that require electrical isolation, transformer-based converter will be a promising solution. However, transformer-based or coupled-inductor-based converters experience issues caused by the leakage inductance, such as high voltage spikes on the switches [13], which necessitates higher-voltage-rated switches, voltage-clamp circuits [20] or snubber circuits [21] that will degrade converters' efficiency. Switched-capacitor converters are well-known for their high power density as they do not contain any magnetic components [14]. However, to achieve a high voltage gain, a large number of capacitors and power switches are required, which greatly increase the cost of the converter [12], [15]. Apart from these topologies, one solution is to utilize a high-switching-frequency resonant inverter that is followed by a rectifier to achieve the high-voltage-gain DC/DC conversion [16]-[19]. The resonant nature of the converter makes it possible to achieve low switching loss despite a 
high switching frequency, which is beneficial for simultaneously attaining high efficiency and high power density [22]. However, this type of converter typically requires precise tuning of its parameters. Since each type of topology has its own advantages and shortcomings, the converter topology should be selected based on the applications and the electrical characteristics of the specified RED stacks.

To harvest energy from RED stack using a high-gain step-up DC/DC converter, various issues such as the maximum power extraction, prevention of harmonics injection, and electrical characteristics matching, need to be resolved. Thus, an optimal design of the RED system (RED stack connected with highgain step-up DC/DC converter) is required, which is still relatively unknown. The existing literature on RED stack has largely focused on novel ion exchange membranes [24], [25], RED stack configuration, and process development [26], [27] and optimization [28], [29]. The electrical characteristic of the RED stack is not well explored, which also gives a challenge for the design of the RED system. In this paper, the RED system is characterized into its steady-state AC and $\mathrm{DC}$ equivalent circuit models for design. The contributions of this paper include: for the first time, (1) the AC impedance of the RED stack is measured and its AC electrical characteristic is explored; (2) the steady-state $\mathrm{DC}$ and $\mathrm{AC}$ equivalent circuit models of the RED system are derived; and (3) a design demonstration of a specified RED system involving an extremely high-gain step-up DC/DC converter with high efficiency is reported.

\section{Configuration And Design Issues of The PROPOSED RED SYSTEM}

The proposed RED system comprises an RED stack and a high step-up DC/DC converter. It can be readily connected to an inverter for $\mathrm{AC}$ power provision to the grid or pump driver system, as illustrated in Fig. 2. Some available solutions for the inverter stage can be found in [30]. The inverter stage will not be discussed in this paper.

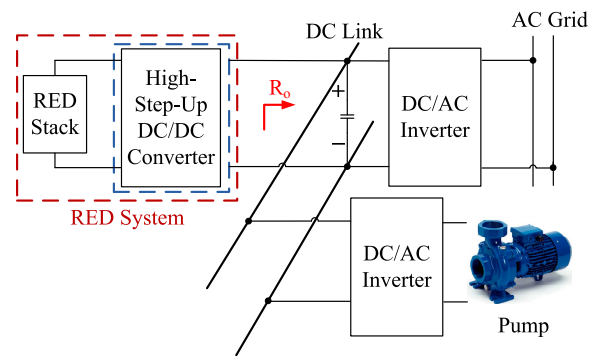

Fig. 2. Structure of a possible RED grid-connected system.

To ensure an optimal design of the RED system, other than ensuring that the high step-up DC/DC converter achieves a high efficiency, another important aspect is maximizing the harvested energy from RED stack. This is possible only if proper design of the high step-up DC/DC converter with regards to the characteristics of the adopted RED stack can be established. The characteristics of the RED stack (such as the power curve, the polarization curve, and the impedance curve) must be considered in the design of the RED system. The polarization curve and the power curve present the output voltage and the output power of the RED stack under different load current levels. They specify the requirements for the input voltage, the power rating and the voltage gain of the converter, and further determine the parameters' design and the components' choice. The impedance curve presents the AC impedance of the RED stack versus different frequencies. It is needed for the design of the buffer capacitor of the DC/DC converter, in order to minimize the harmonic currents from being injected from the converter into the RED. This is important because the injected harmonic currents will affect the operation and life time of the RED stack. A buffer capacitor $C_{i n}$ can be inserted in between the RED stack and the $\mathrm{DC} / \mathrm{DC}$ converter to prevent harmonic current from being injected into the RED stack. A larger buffer capacitor can handle a higher ripple current at the expense of a lower power density. The tolerance of the current ripple should be taken into account in the process of capacitor's selection.

\section{Design Methodology of the RED System}

To let the proposed RED system work well and efficiently, the design of the RED system should achieve following objects: (a) extracting maximum or near maximum power (over $99 \%$ of the maximum output power) from the RED stack; (b) meet the DC link voltage rating requirement (the voltage gain of the high step-up converter should be high enough); (c) the voltage rating and power rating of the converter matches the electrical characteristics of the RED stack; (d) prevent excessive harmonics current being injected into the RED stack. For conditions (a), (b) and (c), they can be met by applying the DC equivalent circuit of the RED system based on the information of polarization curve and power curve of the RED stack. For condition (d), it can be met by applying the AC equivalent circuit model of the RED system based on the information of internal impedance curve of the RED stack.

\section{A. DC equivalent circuit model of the RED system}

The voltage established by the RED stack is of DC form. The DC equivalent model of the RED stack can be simplified as a DC source $E_{\text {stack }}$ that is in series with a DC internal resistance $R_{\text {stack }}$, as shown in Fig. 3(a). The voltage of $E_{\text {stack }}$ is equal to the open-circuit potential. The internal resistance $R_{\text {stack }}$ is related to the internal resistances of membrane piles, water compartment and eletrodes. The high step-up converter can be seen as a kind of load resistance $R_{L}$. $E_{\text {stack }}$ and $R_{\text {stack }}$ can be derived from the polarization curve of the RED stack as shown in Fig. 3(b). $R_{\text {stack }}$ is determined by the slope of the polarization curve.

To extract the maximum power or near maximum power from the RED stack, the load resistance $R_{L}$ must match the internal DC resistance of the RED stack. The suitable load resistance range can be derived by combining the polarization curve and power curve of the RED stack. If over $99 \%$ of maximum $P_{L}$ is guaranteed to be extracted, the load resistance $R_{L}$ should be a value between $R_{L 2}$ and $R_{L 1}$ as shown in Fig. 3(b). Besides, in this case, the output voltage range 


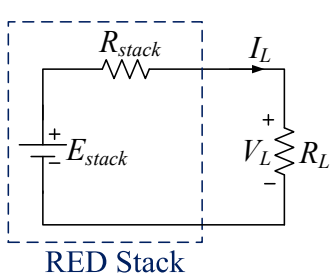

(a)

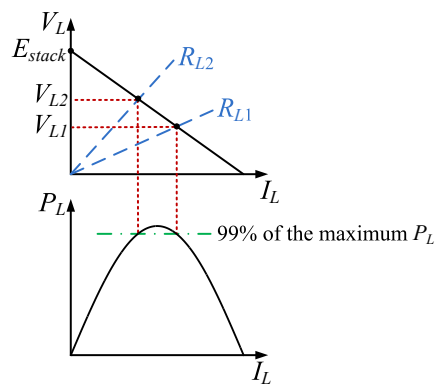

(b)
Fig. 3. (a) DC equivalent circuit of the RED stack with load $R_{L}$ and (b) the diagrams of the polarization curve and power curve.

of the RED stack (input voltage range of the high stepup converter) is from $V_{L 1}$ to $V_{L 2}$. Thus, for the high stepup converter, the requirements include: (a) the equivalent resistance $R_{L}$ of the converter should be in the range of $R_{L 1}$ to $R_{L 2}, R_{L 1} \leq R_{L} \leq R_{L 2}$; (b) the power rating of the converter should be over the maximum $P_{L}$; (c) the voltage rating of the components in the converter should be larger than the maximum voltage stress across components when the input voltage of the converter is $V_{L 2}$; and (d) the designed voltage gain should meet the minimum output voltage requirement when the input voltage of the converter is $V_{L 1}$.

To improve the stability of the RED system, different working conditions of the RED stack must be considered in its design. Both the polarization curve and power curve are varied in different working conditions. Thus, to achieve maximum or near maximum output power of the RED stack, different $R_{L}$ ranges should be met in different working conditions. Assume $R_{L 1 \text { (design) }}$ is the maximum value of $R_{L 1}$ in all possible working conditions and $R_{L 2 \text { (design) }}$ is the minimum value of $R_{L 2}$ in all possible working conditions. When the equivalent DC resistance $R_{L}$ of the converter is in the range of $R_{L 1 \text { (design) }}$ to $R_{L 2 \text { (design) }}\left(R_{L 1(\text { design })} \leq R_{L} \leq R_{L 2 \text { (design })}\right)$, the RED system can achieve maximum or near-maximum output power extraction in all possible working conditions. The corresponding range of the input voltage of the converter can be found by mapping the resistances range $\left(R_{L 1 \text { (design })}\right.$ to $\left.R_{L 2 \text { (design) }}\right)$ to the polarization curves. In these corresponding range, the minimum input voltage determines the minimum required voltage gain of the converter, the maximum input voltage determines the voltage rating of the components in the converter. Besides, the power rating of the converter should be over the maximum output power of the RED stack under these different working conditions. In this way, the voltage rating, power rating, required voltage gain and equivalent resistance of the converter which are appropriately suited for different working conditions, can be derived based on the polarization curve and power curve of the RED stack.

\section{B. AC equivalent circuit model of the RED system}

The AC equivalent circuit model of the RED system is useful for the design of the buffer capacitor inserted between the RED stack and the high step-up DC/DC converter to prevent harmonics current being injected into the RED stack.

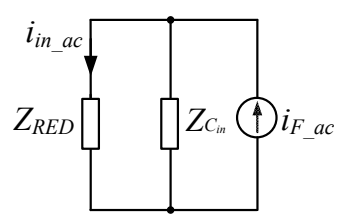

Fig. 4. AC equivalent circuit of the RED system (RED stack with a high step-up DC/DC converter).

Fig. 4 shows the proposed $\mathrm{AC}$ equivalent circuit model of the RED system, of which $Z_{R E D}$ is the AC impedance of the RED stack, $i_{F_{-} a c}$ is the AC equivalent current source representing the harmonic currents that are injected into the system by the high step-up DC/DC converter and $Z_{C_{i n}}$ is the impedance of the buffer capacitor. One important component of the AC equivalent circuit model of the RED system is the AC impedance $Z_{R E D}$ of the RED stack. Best to the authors' knowledge, there is no reported paper describing the $\mathrm{AC}$ impedance of the RED stack. This will be the first time the AC impedance measurement of the RED stack is reported. The AC impedance can be measured by an impedance analyzer with auxiliary circuit. The RED stack is measured at the maximum output power point as determined by the power curve of the RED stack.

The AC current flowing into the RED stack is

$$
i_{\text {in_ac }}=i_{F_{-} a c} \cdot \frac{Z_{C_{i n}}}{Z_{C_{i n}}+Z_{R E D}}
$$

The percentage $m \%$ of $i_{F_{-} a c}$ being injected into the RED stack will be governed by

$$
\frac{\left|Z_{C_{i n}}\right|}{\left|Z_{R E D}+Z_{C_{i n}}\right|} \leq \frac{m}{100} .
$$

The buffer capacitor value should meet the equation (2) based on the current ripple tolerance and the impedance of specific RED stack.

\section{Design Demonstration of a Specified RED SYSTEM}

A design demonstration for a specified RED system is illustrated in this section. Assume the specified RED system is designed for a $110 \mathrm{~V}, 60 \mathrm{~Hz}$ AC power system. Then, the output voltage of the RED system connecting the DC link must be over $155.6 \mathrm{~V}$.

\section{A. Electrical Characteristics of the Specified RED Stack}

1) Specified RED Stack: The operation principle of the RED stack adopted in the proposed system is well-described in the literature [2], [5]. The specified RED stack is mainly built up of two square plates made of PMMA (poly(methyl 2-methylpropenoate)) and a pile of membranes placed in between. The membrane pile comprises 30 pieces of the anion exchange membranes and 31 pieces of the cation exchange membranes (active area $10 \times 10 \mathrm{~cm}^{2}$ ) that are piled in an alternative manner. Two pieces of titanium mesh electrodes (mesh size 1.0 , area $10 \times 10 \mathrm{~cm}^{2}$ ) coated with $\mathrm{Ru} / \mathrm{Ir}$ oxide are inserted in the plates. The flow rates of the two water 
streams and electrolyte are controlled by three peristaltic pumps at constant values of $420 \mathrm{~mL} / \mathrm{min}$. Redox couple of $\mathrm{K}_{3} \mathrm{Fe}(\mathrm{CN})_{6} / \mathrm{K}_{4} \mathrm{Fe}(\mathrm{CN})_{6}$ is recycled through the external loop to provide electrons.

The specified RED stack works on high-concentration solution of $1.2 \mathrm{~mol} / \mathrm{L} \mathrm{NaCl}$, low-concentration solution of 0.02 $\mathrm{mol} / \mathrm{L} \mathrm{NaCl}$, and at feed solutions' temperature of $25^{\circ} \mathrm{C}$. The polarization curve and power curve of the RED stack for the standard condition are plotted as shown in Fig. 5. The opencircuit voltage is around $5.2 \mathrm{~V}$. The generated power is over $0.8 \mathrm{~W}$ when the RED supplies current in the range of 0.28 A to $0.36 \mathrm{~A}$ (output voltage range of $2.26 \mathrm{~V}$ to $2.85 \mathrm{~V}$ ). The power density of membrane area is around $1.4 \mathrm{~W} / \mathrm{m}^{2}$.

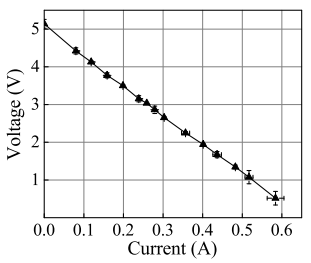

(a)

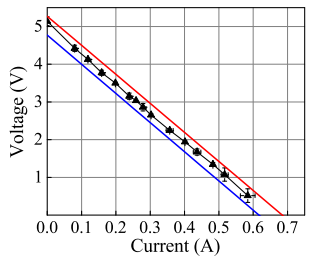

(c)

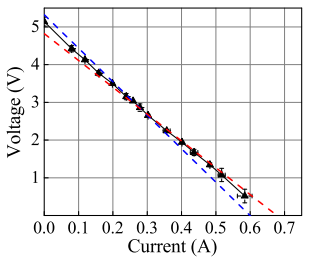

(e)

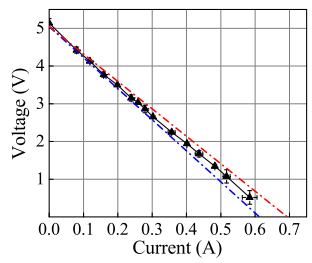

(g)

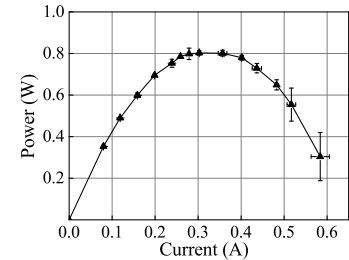

(b)

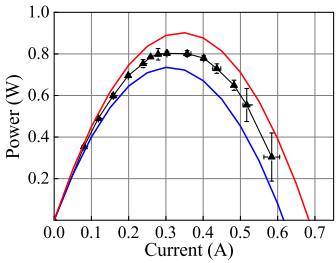

(d)

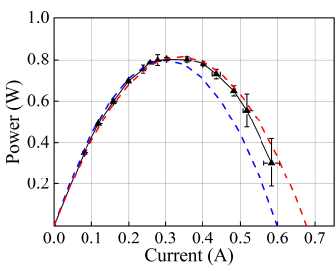

(f)

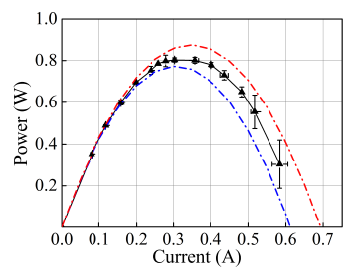

(h)
Fig. 5. (a) The polarization curve and (b) power curve of the RED stack under high-concentration solution of $1.2 \mathrm{~mol} / \mathrm{L} \mathrm{NaCl}$, low-concentration solution of $0.02 \mathrm{~mol} / \mathrm{L} \mathrm{NaCl}$, and feed solutions' temperature of $25^{\circ} \mathrm{C}$. (c) The estimated fluctuation of voltage and (d) power production versus current when the concentration of high concentration solution increased by $20 \%$ (red line) and decreased by $20 \%$ (blue line). (e) The estimated fluctuation of voltage and (f) power production versus current when the concentration of low concentration solution increased by $20 \%$ (red line) and decreased by $20 \%$ (blue line). (g) The estimated fluctuation of voltage and (h) power production versus current when temperature of the feed solutions increased by $20 \%$ (red line) and decreased by $20 \%$ (blue line).

2) Modeling and Analytical Results of the RED Stack under Different Working Conditions: The theoretical open-circuit voltage of an RED stack with $N$ cell pairs is the sum of the electromotive force over all the cation exchange membranes and anion exchange membranes, which can be derived using Nernst equation [23] as:

$$
\begin{aligned}
E_{\text {stack }} & =N\left(v_{A E M}+v_{C E M}\right) \\
& =N\left[\frac{\alpha_{A E M}}{z_{-}}+\frac{\alpha_{C E M}}{z_{+}}\right] \frac{R T}{F} \ln \frac{c_{\text {high }}}{c_{\text {low }}},
\end{aligned}
$$

where $\alpha$ is the permselectivity of the ion exchange membrane with the subscript AEM and CEM referring to the anion exchange membrane and cation exchange membrane, respectively, $R$ is the gas constant $(8.314 \mathrm{~J} /(\mathrm{mol} \mathrm{K})), T$ is the absolute temperature $(\mathrm{K}), F$ is the Faraday constant $(96,485$ $\mathrm{C} / \mathrm{mol}$ ), and $c$ represents the concentration of feed solutions with the subscripts representing either the high-concentration solution and low-concentration solution.

The voltage of the stack is also related to the voltage losses due to the internal resistances of the membrane piles, water compartment and electrodes. The output voltage is proportional to the current in the circuit and is expressed as

$$
V=E_{\text {stack }}-I \cdot R_{\text {stack }} \text {. }
$$

Here, $I$ is the current in the electrical circuit of RED stack and external load, and $R_{\text {stack }}$ refers to the total internal resistance of the stack, and is given as

$$
R_{\text {stack }}=\frac{N}{A}\left(\bar{R}_{A E M}+\bar{R}_{C E M}+f \cdot \frac{d_{h}}{c_{h}}+f \cdot \frac{d_{l}}{c_{l}}\right)+R_{e l} .
$$

Here, $A$ is the effective area of an individual ion exchange membrane contacts with the feed water, $\bar{R}_{A E M}$ and $\bar{R}_{C E M}$ are respectively the averaged area resistance of anion exchange membrane and cation exchange membrane, $d$ is the unitary inter membrane distance of water compartments, $c_{h}$ and $c_{l}$ are the conductivity of high-concentration and low-concentration solutions within the compartments respectively, $R_{e l}$ is the resistance of the electrode and $f$ is the negative effect of spacers on the water compartment resistance [31]. The relationship of solutions' temperature $T$ and the corresponding conductivity $c_{h}$ and $c_{l}$ are assumed to be linear at $2.1 \% /{ }^{\circ} \mathrm{C}$.

TABLE I

PARAMETERS OF OUR RED STACK UNDER DIFFERENT WORKING CONDITIONS

\begin{tabular}{|c|c|c|c|c|c|}
\hline $\begin{array}{c}\text { Working } \\
\text { Condition }\end{array}$ & $\begin{array}{c}\text { HS* } \\
(\mathrm{mol} / \mathrm{L})\end{array}$ & $\begin{array}{c}\mathrm{LS}^{*} \\
(\mathrm{~mol} / \mathrm{L})\end{array}$ & $\begin{array}{c}\text { Feed Solution } \\
\text { Temperature }\left({ }^{\circ} \mathrm{C}\right)\end{array}$ & $\begin{array}{c}\text { Polarization } \\
\text { Curve }\end{array}$ & $\begin{array}{c}\text { Power } \\
\text { Curve }\end{array}$ \\
\hline Standard & 1.2 & 0.02 & 25 & $5(\mathrm{a})$ & $5(\mathrm{~b})$ \\
\hline $1(\mathrm{a})$ & $1.2+20 \%$ & 0.02 & 25 & $5(\mathrm{c})$ & $5(\mathrm{~d})$ \\
\hline $1(\mathrm{~b})$ & $1.2-20 \%$ & 0.02 & 25 & $5(\mathrm{c})$ & $5(\mathrm{~d})$ \\
\hline $2(\mathrm{a})$ & 1.2 & $0.02+20 \%$ & 25 & $5(\mathrm{e})$ & $5(\mathrm{f})$ \\
\hline $2(\mathrm{~b})$ & 1.2 & $0.02-20 \%$ & 25 & $5(\mathrm{e})$ & $5(\mathrm{f})$ \\
\hline $3(\mathrm{a})$ & 1.2 & 0.02 & $25+20 \%$ & $5(\mathrm{~g})$ & $5(\mathrm{~h})$ \\
\hline $3(\mathrm{~b})$ & 1.2 & 0.02 & $25-20 \%$ & $5(\mathrm{~g})$ & $5(\mathrm{~h})$ \\
\hline
\end{tabular}

* HS: high-concentration solution, LS: low-concentration solution.

Based on equations (3)-(5) and the experiment results given in Fig. 5(a) and Fig. 5(b), the polarization and power curves of the RED stack under different working conditions are derived as shown in Fig. 5(c) to Fig. 5(h). The parameters of the specified RED stack under different working conditions are summarized in Table I. 


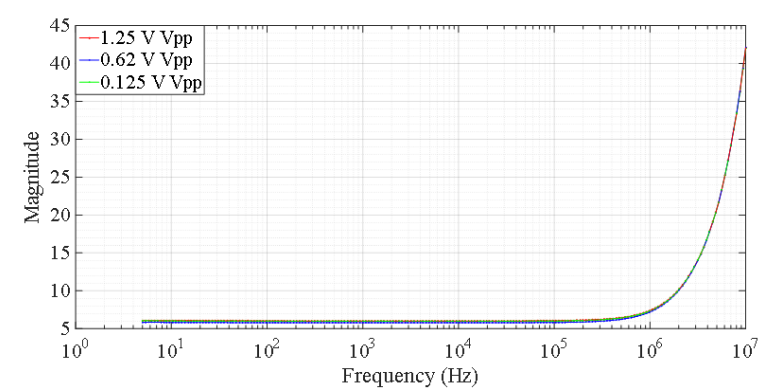

(a)

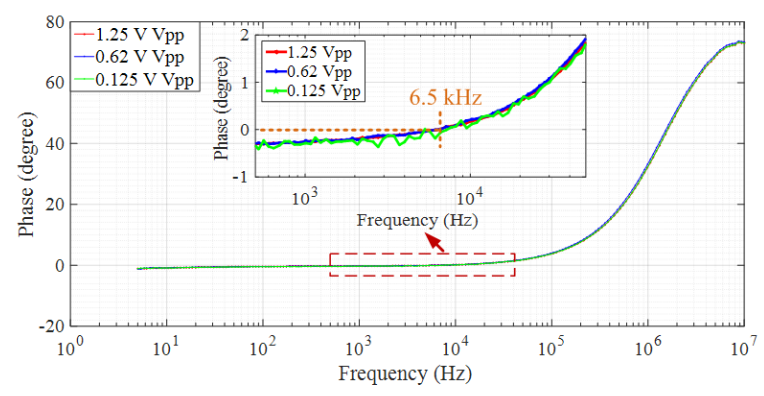

(b)

Fig. 6. The AC impedance (a) magnitude and (b) phase angle of RED stack with frequency swept from $5 \mathrm{~Hz}$ to $10 \mathrm{MHz}$.

3) AC Impedance of the RED Stack: The AC impedance of the RED stack is measured at the maximum output power point of the RED stack, which is at output voltage of $2.53 \mathrm{~V}$ and output current of $0.33 \mathrm{~A}$. Three different voltage levels of the AC voltage source $V_{a c}$ (peak-to-peak values are $0.125 \mathrm{~V}$, $0.62 \mathrm{~V}$, and $1.25 \mathrm{~V}$ respectively) are applied in this set of measurements. The magnitude and phase angle of the RED stack's AC impedance versus frequency are plotted in Fig. 7. It shows that the AC impedance of the RED stack is consistent with negligible difference under various voltage level of $\mathrm{AC}$ source. It means the $\mathrm{AC}$ impedance of RED stack is quite stable for different levels of injected harmonic components. The self-resonant frequency (the point that impedance phase is zero degree) is around $6.5 \mathrm{kHz}$.

\section{B. High-Gain Step-Up DC/DC Converter}

Given the existing RED stack, under the different working conditions and at its maximum or near maximum output power points, its output voltage will be in the range of $2 \mathrm{~V}$ to $3 \mathrm{~V}$. To boost the voltage to $155.6 \mathrm{~V}$, the voltage gain of the high stepup DC/DC converter should be 51.9 times (for $3 \mathrm{~V}$ ) to 77.8 times $(2 \mathrm{~V})$. With consideration of such high voltage gain, the efficiency, the cost and the power rating of the RED stack, resonant converter that comprises a high-switching-frequency resonant inverter and a rectifier is adopted in this RED system. Fig. 7(a) shows the schematic diagram of the converter. A buffer capacitor $C_{i n}$ is inserted in between the RED stack and the high step-up converter as shown in Fig. 7(a). The operating principle and the design considerations of this converter are described in [18], [19]. Only brief aspects of the design related to the RED application are summarised here.

1) Operating Principle of Inverter Stage: The network comprising $L_{F}, C_{p}, L_{r 2}$ and $C_{r 2}$ is designed to achieve

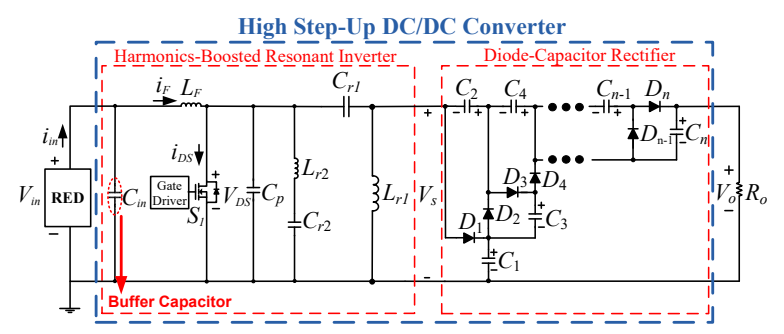

(a)

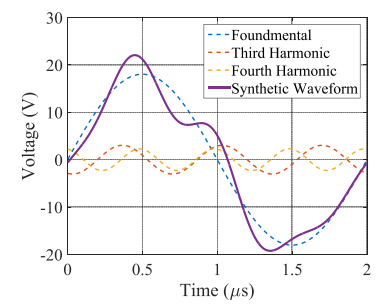

(b)

Fig. 7. (a) The schematic diagram of the high-gain step-up DC/DC converter and (b) synthetic waveform $V_{s}$ with high level of fundamental frequency component and low level of third and fourth harmonics components.

appropriate voltage stress across the active switch $S_{1}$ and a low switching loss that is resulted from zero-voltage switching (ZVS). $L_{r 2}$ and $C_{r 2}$ are designed to resonate at 2 nd harmonic frequency $f_{2} . C_{r 1}$ and $L_{r 1}$ are designed to resonate near the switching frequency $f_{s}$. This resonant tank boosts the output voltage $V_{s}$ by amplifying the fundamental component of $V_{D S}$ by $\frac{R_{e q}}{2 \pi f_{s} L_{r 1}}$ times. Here, $R_{e q}$ is the equivalent input resistance of the diode-capacitor rectifier with the load. $V_{s}$ contains a high level of fundamental frequency component and low levels of 3rd and 4th harmonic frequency components, which increase the peak value of $V_{s}$ (see Fig. 7(b)).

2) Operating Principle of Diode-Capacitor Rectifier Stage: Assume that the maximum absolute values of the positive cycle and negative cycle of $V_{s}$ are $V_{\text {smaxt }}$ and $V_{\text {smax- }}$. When $V_{s}$ reaches $V_{\text {smax }}$, diodes $D_{1}, D_{3}, \cdots, D_{n}$ conduct. At the same time, the capacitors $C_{2}, C_{4}, \cdots, C_{n-1}$ are discharged and capacitors $C_{1}, C_{3}, \cdots, C_{n}$ are charged. When $V_{s}$ reaches $-V_{\text {smax }- \text {, diodes }} D_{2}, D_{4}, \cdots, D_{n-1}$ conduct. In the meantime, capacitors $C_{2}, C_{4}, \cdots, C_{n-1}$ are charged and capacitors $C_{1}, C_{3}, \cdots, C_{n}$ are discharged. Thus, the voltage across capacitor $C_{1}$ is $V_{s m a x+}$, the voltage across capacitor $C_{2}, \cdots, C_{n}$ are $V_{\text {smax }}+V_{\text {smax }}$, and the output voltage is $V_{o}=\frac{n+1}{2} V_{\text {smax }}+\frac{n-1}{2} V_{\text {smax }}$. If the positive peak value of $V_{s}$ is increased by $\triangle V_{s \max +}$, the output voltage $V_{o}$ of the overall converter will be increased by $\frac{n+1}{2} \triangle V_{s m a x+}$. The generic equation of the voltage gain of this high stepup converter is $\frac{2 R_{o}}{n \pi \omega_{s} L_{s}}$ (where $\omega_{s}=2 \pi f_{s}$ ), which has been reported in [18].

\section{Parameters Design Based on Equivalent Circuit Models}

The requirements for converter's voltage rating, power rating and voltage gain can be derived based on the DC equivalent circuit model of RED system. Different working conditions of RED stack shown in Table I are considered to design the RED system. If the RED stack is to work at the maximum or near-maximum output power point $(\geq 99 \%$ of the maximum 
TABLE II

EQUIVALENT INPUT RESISTANCE AND CORRESPONDING INPUT VOLTAGE OF THE CONVERTER

\begin{tabular}{|c|c|c|c|c|}
\hline Working Conditions & $R_{L 1}(\Omega)$ & $R_{L 2}(\Omega)$ & $V_{L 1}(\mathrm{~V})$ & $V_{L 2}(\mathrm{~V})$ \\
\hline Standard & 6.28 & 10.18 & 2.5 & 2.59 \\
\hline 1(a) & 6.51 & 8.91 & 2.65 & 2.74 \\
\hline 1(b) & 7.09 & 8.79 & 2.39 & 2.48 \\
\hline 2(a) & 6.0 & 8.39 & 2.52 & 2.61 \\
\hline 2(b) & 7.8 & 10.07 & 2.49 & 2.58 \\
\hline 3(a) & 6.08 & 8.5 & 2.61 & 2.7 \\
\hline 3(b) & 6.97 & 9.79 & 2.45 & 2.54 \\
\hline
\end{tabular}

$P_{L}$ ), then $R_{L}$ should be in a range of $R_{L 1}$ to $R_{L 2}$ as shown in Fig. 3(b). Based on the polarization curves and power curves given in Fig. 5, the values of $R_{L 1}$ and $R_{L 2}$, which represent the equivalent input resistance ranges for different working conditions of the RED stack, can be found and are shown in Table II. Taking into consideration of all the working conditions of the RED stack, for the converter design, $R_{L 1(\text { design })}=$ $\max \left(R_{L 1}\right.$ (standard, 1(a), 1(b), $\left.\left.\cdots, 3(\mathrm{~b})\right)\right)=7.8 \Omega$ and $R_{L 2(\text { design })}=\min \left(R_{L 2}(\operatorname{standard}, 1(\mathrm{a}), 1(\mathrm{~b}), \cdots, 3(\mathrm{~b}))\right)=$ $8.39 \Omega$. When the equivalent input resistance of the converter being $R_{L 1 \text { (design) }} \leq R_{L} \leq R_{L 2 \text { (design) }}$, the RED system will achieve maximum or near-maximum output power extraction for all the possible working conditions.

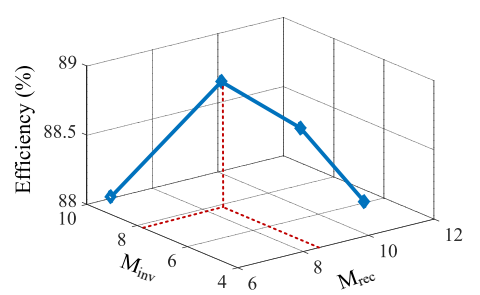

Fig. 8. Efficiency versus the voltage gain of two stages of the converter with input voltage $2.5 \mathrm{~V}$, input power $0.8 \mathrm{~W}$, and 67 times voltage gain.

The corresponding range of input voltage of the converter can be found by mapping the resistances $\left(R_{L 1 \text { (design })}\right.$ and $\left.R_{L 2(\text { design })}\right)$ to the polarization curves in Fig. 5 . These voltage values are shown in Table II. The minimum possible input voltage is $2.39 \mathrm{~V}$, which is generated when the RED stack is working in condition 1(b). This voltage value defines the minimum voltage gain required for the converter. As the RED system is designed for a $110 \mathrm{~V}$ AC power system, the voltage gain of the converter should be at least 65.1 times to boost the input voltage of $2.39 \mathrm{~V}$ to be over $155.6 \mathrm{~V}$. As the voltage gain should be over 65.1 times, 67 times voltage gain is adopted here for the converter. As illustrated in [18], there should be a optimal voltage gain combination for the converter to achieve an optimal efficiency. A simulation study is conducted for the circuit. Fig. 8 shows the variation of efficiency for different combinations of voltage gains of the inverter stage $\left(M_{i n v}\right)$ and rectifier stage $\left(M_{r e c}\right)$. Thus, to get an optimal efficiency of the converter with 67 times voltage gain, the voltage gain of the diode-capacitor rectifier stage adopted in this converter is around 9 times ( 9 capacitors and 9 diodes are adopted in this stage).

From the Table II, the maximum possible input voltage is found as $2.74 \mathrm{~V}$, which is generated by working condition 1(a). This voltage value determines the voltage rating of the components. At the maximum output voltage of $2.74 \mathrm{~V}$ and voltage gain of 67 times, the output voltage will be $183.6 \mathrm{~V}$. Thus, for the diodes and capacitors (except capacitor $C_{1}$ ) in the diode-capacitor rectifier, the voltage rating should be $\frac{183.6}{9} \times$ $2=40.8 \mathrm{~V}$. The voltage rating of capacitor $C_{1}, C_{r 1}$ and $C_{r 2}$ should be $\frac{183.6}{9}=20.4 \mathrm{~V}$. The voltage rating of switch $S_{1}$ of the resonant inverter stage should be $2.74 \times 4.2=11.5 \mathrm{~V}$.

The load resistance $R_{o}$ of the converter can be calculated as $\frac{V_{o}{ }^{2}}{\eta \cdot P_{i n}}$, where $\eta$ is the efficiency of the converter, $P_{i n}$ is the maximum output power of the RED stack, and $V_{o}$ is the output voltage of the converter. To achieve maximum output power extraction, the grid-connected inverter must be operated to have an equivalent DC input resistance of $R_{o}$.

The design of the buffer capacitor can be based on the AC equivalent circuit model in Fig. 4. The switching frequency of the converter in the proposed system is set at $500 \mathrm{kHz}$. According to Fig. 7, the AC impedance $Z_{R E D}$ at $500 \mathrm{kHz}$ frequency is $6.35 \angle 18.5^{\circ} \Omega$. Based on the equation (2), if a $47 \mu \mathrm{F}$ WCAP-ATG8 series capacitor (of which the effective impedance at $500 \mathrm{kHz}$ when the capacitor is biased at $2.5 \mathrm{~V}$ DC at $25^{\circ} \mathrm{C}$, is measured as $0.187 \angle-13.54^{\circ} \Omega$ ) is adopted, then $m=\frac{\left|0.187 \angle-13.54^{\circ}\right|}{\left|6.51 \angle 17.626^{\circ}\right|} \times 100=2.9$.

\section{EXPERIMENTAL RESULTS}

The parameters of the high-gain step-up DC/DC converter is designed based on the discussion given in Section IV-C. The parameters are given in Table III. The buffer capacitor adopted is a $47 \mu \mathrm{F}$ WCAP-ATG8 series capacitor. The switching frequency is $500 \mathrm{kHz}$. The driver circuit of the converter is shown in Fig. 9. To verify the voltage gain, the converter is first tested with a programmable DC input power supply. Experimental results of the output voltage and input power versus the input voltage are plotted as illustrated in Fig. 11. Fig. 11 shows that even when the converter is working at the minimum input voltage of $2.39 \mathrm{~V}$ (minimum value of $V_{L 1}$ in Table II), the output voltage is $161 \mathrm{~V}$, which is above the required voltage of $155.6 \mathrm{~V}$. Fig. 12 shows the measured

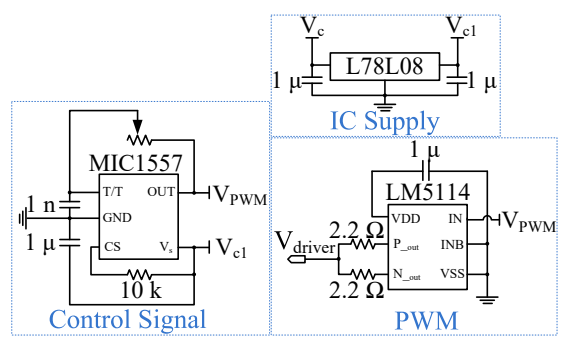

Fig. 9. Driver circuit of the high step-up DC/DC converter.

input power versus input current (the brown line) plot of the converter and the power production versus the output current plots of the RED stack under different working conditions. According to Fig. 12, a power of $99.93 \%, 99.9 \%, 99.63 \%$, $99.45 \%, 99 \%, 99.6 \%$ and $99.33 \%$ of the maximum power can be extracted from the RED stack under the standard condition and condition 1(a), 1(b), 2(a), 2(b), 3(a), and 3(b), respectively. Thus, when the concentration or feed solution temperature 
TABLE III

PARAMETERS OF HIGH STEP-UP DC/DC CONVERTER

\begin{tabular}{|c|c|c|c|c|c|c|c|c|c|}
\hline$L_{F}$ & $4.6 \mu \mathrm{H}$ & $C_{p}$ & $4.7 \mathrm{nF}$ & $L_{r 2}$ & $3.2 \mu \mathrm{H}$ & $C_{r 2}$ & $7.93 \mathrm{nF}$ & $L_{r 1}$ & $11.3 \mu \mathrm{H}$ \\
\hline$C_{r 1}$ & $8.93 \mathrm{nF}$ & MOSFET $S_{1}$ & GS61004B & $C_{1}, C_{2}, \cdots, C_{9}$ & $0.1 \mu \mathrm{F}$ & $D_{1}, D_{2}, \cdots, D_{9}$ & DFLS160-7 & $R_{o}$ & $40.46 \mathrm{k} \Omega$ \\
\hline
\end{tabular}

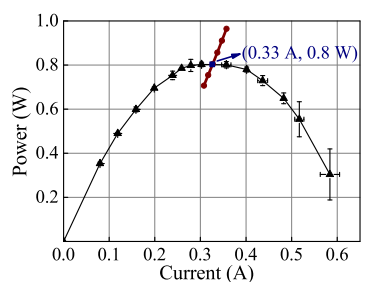

(a)

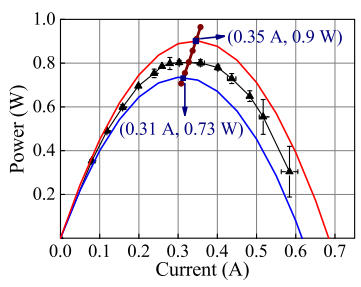

(b)

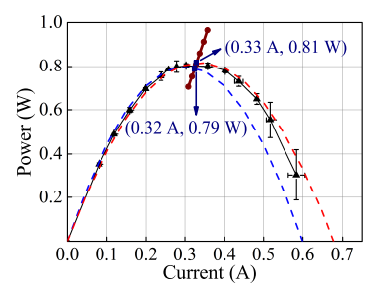

(c)

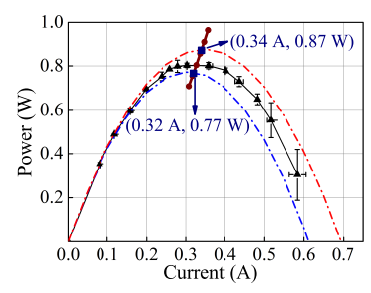

(d)

Fig. 12. The measured input power versus input current (brown line) of the high step-up DC/DC converter and the measured power production versus output current of RED stack (a) under the standard working condition, the estimated power production of RED stack under (b) working condition 1(a) (red line) and 2(a) (blue line), (c) working condition 2(a) (red line) and 2(b) (blue line), and (d) working condition 3(a) (red line) and 3(b) (blue line).

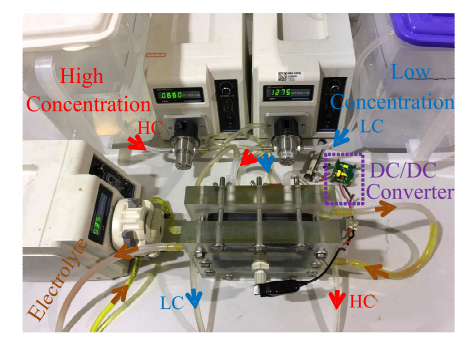

Fig. 10. Prototype of the RED system. HC represents high concentration. LC represents low concentration.

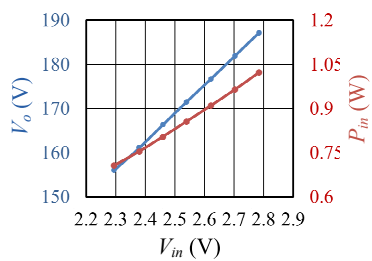

(a)

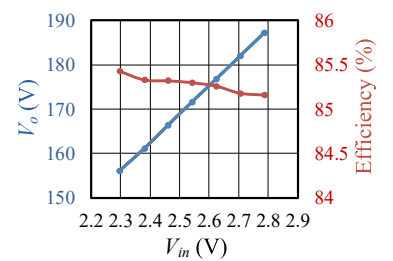

(b)
Fig. 11. Experimental measurement of (a) output voltage and input power and (b) output voltage and efficiency versus variable input voltage of the high step-up DC/DC converter.

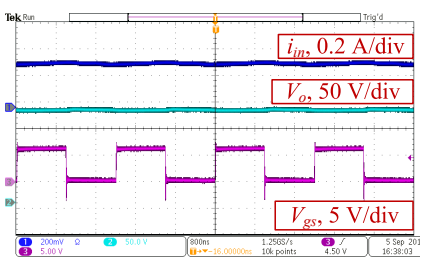

(a)

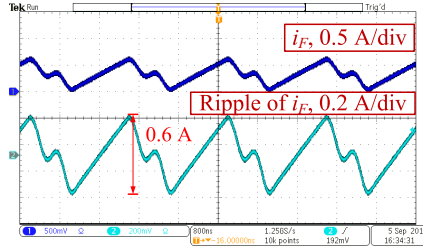

(c)

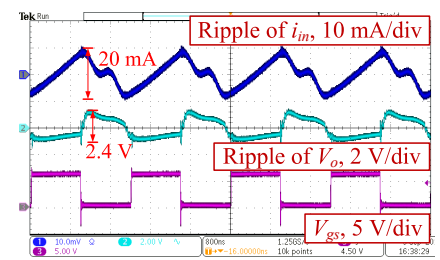

(b)

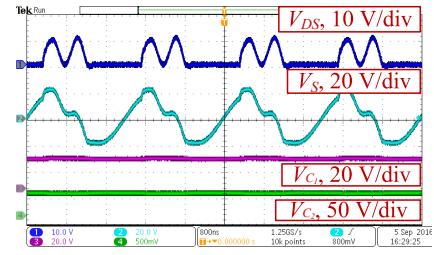

(d)
Fig. 13. (a) Waveforms of output current $i_{i n}$ of RED stack, output voltage $V_{o}$ of the RED system, and driving signal $V_{g s}$ of the converter, (b) their ripples, (c) $i_{F}$ and its ripple, and (d) key waveforms of DC/DC converter when the RED stack works at standard working condition without fluctuations. fluctuates at $\pm 20 \%$, the converter is capable of operating the RED stack at the maximum or near-maximum power point.

Fig. 10 shows the prototype of the RED system. The stepup converter is tested together with the RED stack. Under the standard working condition, the output voltage of the RED stack is $2.53 \mathrm{~V}$, and its output current is $0.33 \mathrm{~A}$ and output power is $0.84 \mathrm{~W}$, indicating that the RED stack is working at its maximum output power point. The output voltage $V_{o}$ of the system is $170.4 \mathrm{~V}$. The voltage gain of the DC/DC converter is 67.3 times and the efficiency of the converter is $85.3 \%$. As $99.93 \%$ of the maximum power is extracted from the RED stack, the efficiency of the whole RED system is 85.24\%. Fig. 13(a) and Fig. 13(b) show the output current of

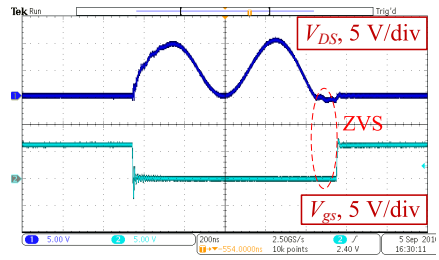

Fig. 14. $V_{D S}$ and $V_{g s}$.

the RED stack, the output voltage and the driving signal of the converter. The output voltage $V_{o}$ of the RED system is 170.4 $\mathrm{V}$, and the ripple is $2.4 \mathrm{~V}$, which is $1.4 \%$ of $V_{o}$. The output current $i_{i n}$ of the RED stack is around $330 \mathrm{~mA}$, and the current ripple is $20 \mathrm{~mA}$. The current ripple of $i_{F}$ is $0.6 \mathrm{~A}$ as shown in Fig. 13(c). Thus, the ratio between ripple of $i_{i n}$ and $i_{F}$ is 3.3\%, which is a slightly higher than the theoretically designed $m \%$ value of $2.9 \%$. The discrepancy is attributed to the presence of parasitic impedances in the circuit and high-order harmonics in the current. Fig. 13(d) shows the output voltage $V_{s}$ of the resonant inverter stage and the voltage across the capacitors in the rectifier stage of the DC/DC converter. As mentioned in the discussion, the positive peak value of $V_{s}$ is slightly higher than the negative peak value due to the voltage harmonic components. The voltage $V_{C 2}$ across capacitor $C_{2}$ is almost twice of that across capacitor $C_{1}$ which verifies the operation of the rectifier. Fig.14 shows the waveforms of voltage $V_{D S}$ on switch $S_{1}$ and driver's signal $V_{g s}$, which indicates that zero- 
voltage-switching (ZVS) is achieved.

About $0.84 \mathrm{~W}$ has been successfully harvested from an RED stack prototype with a volume of $3.67 \times 10^{-3} \mathrm{~m}^{3}$ (with external dimensions: $8.4 \mathrm{~cm} \times 20.9 \mathrm{~cm} \times 20.9 \mathrm{~cm}$ ) at a membrane power density of $1.4 \mathrm{~W} / \mathrm{m}^{2}$. As an estimation, about 20,000 RED stacks of this size can be fitted into a standard 40 -ft container box (with internal dimensions of $1204 \mathrm{~cm} \times 269 \mathrm{~cm} \times 235 \mathrm{~cm}$ ). This suggests that a scaled-up version of the RED system of the size of such container box can provide about 16.8 $\mathrm{kW}$. Since this type of renewable energy can be continuously harvested, this estimated figure signifies the huge potential of the RED technology, particularly when there is much scope for increasing the power per square meter in membrane technology.

\section{CONCLUSIONS}

In this paper, a configuration of RED system (RED stack with high-gain step-up DC/DC converter) suitable for gridinterface is proposed. The characteristics of the RED stack under different working conditions is derived and used for the design of the converter interface. The polarization curve and power curve of the RED stack, combining the DC equivalent circuit model of the RED system, are used to determine the maximum power range and the corresponding operating voltage range of the RED stack. These parameters serve as the input voltage and power rating of the converter. The proposed system comprises a buffer capacitor between the RED stack and the converter, which prevents harmonics produced by the converter from affecting the operation and lifetime of the RED stack. The buffer capacitor is designed using the AC impedance curve of the RED stack and the AC equivalent circuit model of the RED system. In the prototype, the RED stack works at maximum output power point and the converter achieves a voltage gain of 67.3 times and an efficiency of $85.3 \%$.

\section{ACKNOWLEDGMENT}

We thank the funding support from the Strategic Research Theme (Clean Energy) of the University of Hong Kong. The authors like to thank Mr Sitthisak Kiratipongvoot for his help in assisting with the measurement of the AC impedance of the RED stack.

\section{REFERENCES}

[1] N. Y. Yip, D. A. Vermaas, K. Nijmeijer, and M. Elimelech, "Thermodynamic, energy efficiency, and power density analysis of reverse electrodialysis power generation with natural salinity gradients," Environ. Sci. \& Technol., vol. 48, no. 9, pp. 4925-4936, Apr. 2014

[2] J. W. Post, H. V. Hamelers, and C. J. Buisman, "Energy recovery from controlled mixing salt and fresh water with a reverse electrodialysis system," Environ. Sci. \& Technol., vol. 42, no. 15, pp. 5785-5790, Jul. 2008.

[3] J. N. Weinstein and F. B. Leitz, "Electric power from differences in salinity: the dialytic battery," Science, vol. 191, no. 4227, pp. 557-559, Feb. 1976.

[4] B. E. Logan and M. Elimelech, "Membrane-based processes for sustainable power generation using water," Nature, vol. 488, no. 7411, pp. 313-319, Aug. 2012.

[5] D. A. Vermaas, M. Saakes, and K. Nijmeijer, "Doubled power density from salinity gradients at reduced intermembrane distance," Environ. Sci. \& Technol., vol. 45, no. 16, pp. 7089-7095, Jul. 2011.
[6] J. Veerman, M. Saakes, S. J. Metz, and G. J. Harmsen, "Reverse electrodialysis: evaluation of suitable electrode systems," Journal of Appl. Electrochem., vol. 40, no. 8, pp. 1461-1474, Aug. 2010.

[7] M. Tedesco, C. Scalici, D. Vaccari, A. Cipollina, A. Tamburini, and G. Micale, "Performance of the first reverse electrodialysis pilot plant for power production from saline waters and concentrated brines," Journal of Membrane Sci., vol. 500, pp. 33-45, Feb. 2016.

[8] M. Tedesco, A. Cipollina, A. Tamburini, and G. Micale, "Towards 1 $\mathrm{kW}$ power production in a reverse electrodialysis pilot plant with saline waters and concentrated brines," Journal of Membrane Sci., vol. 522, pp. 226-236, Jan. 2017.

[9] Y. Hu, W. Cao, S. J. Finney, W. Xiao, F. Zhang, and S. F. McLoone, "New modular structure DC-DC converter without electrolytic capacitors for renewable energy applications," IEEE Trans. on Sustainable Energy, vol. 5, no. 4, pp. 1187-1192, Oct. 2014.

[10] C. T. Pan and C. M. Lai, "A high-efficiency high step-up converter with low switch voltage stress for fuel-cell system applications," IEEE Trans. on Ind. Electron., vol. 57, no. 6, pp. 1998-2006, Jun. 2010.

[11] S. K. Changchien, T. J. Liang, J. F. Chen, and L. S. Yang,"Novel high step-up DC-DC converter for fuel cell energy conversion system," IEEE Trans. on Ind. Electron., vol. 57, no. 6, pp. 2007-2017, Jun. 2010.

[12] I. Laird and D. D. C. Lu, "High step-up DC/DC topology and MPPT algorithm for use with a thermoelectric generator," IEEE Trans. on Power Electron., vol. 28, no. 7, pp. 3147-3157, Jul. 2013.

[13] Y. Tang, T. Wang, and Y. He, "A switched-capacitor-based activenetwork conveter with high voltage gain," IEEE Trans. on Power Electron., vol. 29, no. 6, pp. 2959-2968, Jun. 2014.

[14] D. Cao and F. Z. Peng, "Multiphase multilevel modular DC-DC converter for high-current high-gain TEG application," IEEE Trans. on Ind. Electron., vol. 47, no. 3, pp. 1400-1408, May-Jun. 2011.

[15] H. Choi, M. Ciobotaru, M. Jang and V. G. Agelidis, "Performance of medium-voltage DC-bus PV system architecture utilizing high-gain DCDC converter," IEEE Trans. on Sustainable Energy, vol. 6, no. 2, pp. 464-473, Apr. 2015.

[16] L. Raymond, W. Liang, J. Choi, and J. Rivas, " $27.12 \mathrm{MHz}$ large voltage gain resonant converter with low voltage stress," in IEEE Energ. Conv. Cong. and Expo. (ECCE), pp. 1814-1821, Sep. 2013.

[17] L. Raymond, W. Liang, K. Surakitbovorn, and J. R. Davila, " $27.12 \mathrm{MHz}$ isolated high voltage gain multi-level resonant DC-DC converter," in IEEE Energ. Conv. Cong. and Expo. (ECCE), pp. 5074-5080, Sep. 2015.

[18] Y. Huang, C. Y. Lai, S. Xiong, S. C. Tan, and S. Y. R. Hui, "Non-isolated high step-up resonant DC/DC converter," in IEEE Energy Conversion Congress \& Expo (ECCE), Sep. 2016.

[19] Y. Huang, S. Xiong, S. C. Tan, and S. Y. R. Hui, "Non-isolated harmonics-boosted resonant DC/DC converter with high-step-up gain," IEEE Trans. on Power Electro., vol. PP, no. 99, pp. 1-1, Nov. 2017.

[20] Y. Zhao, W. Li, and X. He, "Single-phase improved active clamp coupled-inductor-based converter with extended voltage doubler cell," IEEE Trans. on Power Electro., vol. 27, no. 6, pp. 2869-2878, Jun. 2012.

[21] R. J. Wai and R. Y. Duan, "High step-up converter with coupledinductor," IEEE Trans. on Power Electron., vol. 20, no. 5, pp. 10251035, Sep. 2005.

[22] J. M. Rivas, Y. Han, O. Leitermann, A. D. Sagneri, and D. J. Perreault, "A high-frequency resonant inverter topology with low-voltage stress," IEEE Trans. on Power Electro., vol. 23, no. 4, pp. 1759-1771, Jul. 2008.

[23] J. Veerman, J. W. Post, M. Saakes, S. J. Metz, and G. J. Harmsen, "Reducing power losses caused by ionic shortcut currents in reverse electrodialysis stacks by a validated model," Journal of Membrane Science, vol. 310, no. 1, pp. 418-430, Mar. 2008.

[24] E. Guler, Y. Zhang, M. Saakes, and K. Nijmeijer, "Tailor-made anionexchange membranes for salinity gradient power generation using reverse electrodialysis," ChemSusChem, vol. 5, no. 11, pp. 2262-2270, 2012.

[25] J. G. Hong and Y. Chen, "Nanocomposite reverse electrodialysis (RED) ion-exchange membranes for salinity gradient power generation," Journal of Membrane Sci., vol. 460, pp. 139-147, Jun. 2014.

[26] D. A. Vermaas, M. Saakes, and K. Nijmeijer, "Power generation using profiled membranes in reverse electrodialysis," Journal of Membrane Sci., vol. 385-386, no. 1-2, pp. 234-242, Dec. 2011.

[27] S. Pawlowski, J. G. Crespo, and S. Velizarov, "Pressure drop in reverse electrodialysis: experimental and modeling studies for stacks with variable number of cell pairs," Journal of Membrane Sci., vol. 462, pp. 96-111, Jul. 2014.

[28] W. Li, W. B. Krantz, E. R. Cornelissen, J. W. Post, A. R. D. Verliefde, and C. Y. Tang, "A novel hybrid process of reverse electrodialysis 
and reverse osmosis for low energy seawater desalination and brine management," Applied Energy, vol. 104, pp. 592-602, Apr. 2013.

[29] Y. Mei and C. Y. Tang, "Co-locating reverse electrodialysis with reverse osmosis desalination: synergies and implications," Journal of Membrane Sci., 2017.

[30] R. Teodorescu, M. Liserre, and P. Rodriguez, "Grid Converters for Photovoltaic and Wind Power Systems," vol. 29, John Wiley \& Sons, 2011.

[31] J. Veerman, M. Saakes, S. J. Metz, and G. J. Harmsen, "Reverse electrodialysis: a validated process model for design and optimization," Chemical Engineering Journal, vol. 166, no. 1, pp. 256-268, Jan. 2011.

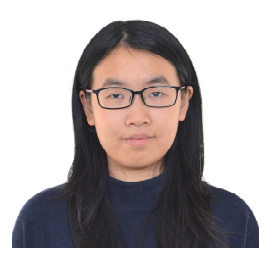

Ying Huang received the B.Eng. Degree in electrical engineering from the Wuhan University, Wuhan, China, in 2013. She is currently working toward the $\mathrm{PhD}$ degree in electrical and electronics engineering at the University of the Hong Kong, Hong Kong.

Her current research interests include switchedcapacitor converter, resonant converter and renewable energy applications. Miss Huang is the recipient of the best paper award at the 8th Annual IEEE Energy Conversion Congress \& Expo (IEEE ECCE 2016).

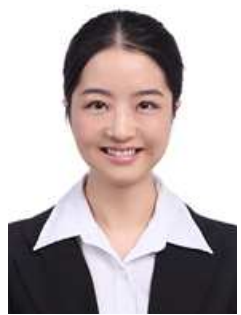

Ying Mei received the B.Eng. degree in Environmental Science from Northeastern University, China, in 2011, the M.Eng. degree in Environmental Engineering from Beijing Normal University, China, in 2014. From June 2014 to July 2015, she worked as a Research Assistant in Civil Engineering from the University of Hong Kong. She is currently a $\mathrm{PhD}$ candidate of Civil Engineering at the University of Hong Kong.

Her research interests include membrane technology, desalination, and clean energy.

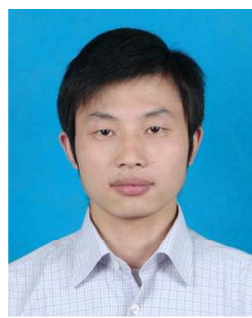

Song Xiong (M'15) was born in China. He received the B.Eng. and M.Eng. degrees in college of electrical and electronic engineering from Huazhong University of Science and Technology, Wuhan, China, in 2007 and 2009, respectively. He received the PH.D. degree in the department of Electronic and Information Engineering (EIE), The Hong Kong Polytechnic University, Hong Kong in 2014. From January 2009 to January 2010, he worked as Research Assistant in Department of Electronic and Information Engineering, The Hong Kong Polytechnic University. He works as Research Assistant, Research Associate, Postdoctoral Fellow in Department of Electrical and Electronic Engineering, The University of Hong Kong, Hong Kong since October, 2013. His research interests switchedcapacitor converter, resonant converter and clean energy technologies. $\mathrm{He}$ is the recipient of the best paper award at the 8th Annual IEEE Energy Conversion Congress \& Expo (IEEE ECCE 2016).

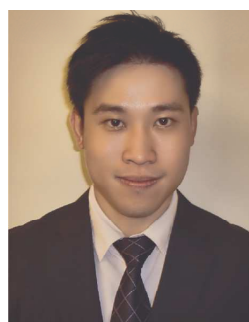

Siew-Chong Tan (M'06-SM'11) received the B.Eng. (Hons.) and M.Eng. degrees in electrical and computer engineering from the National University of Singapore, Singapore, in 2000 and 2002, respectively, and the Ph.D. degree in electronic and information engineering from the Hong Kong Polytechnic University, Hong Kong, in 2005.

From October 2005 to May 2012, he worked as Research Associate, Postdoctoral Fellow, Lecturer, and Assistant Professor in Department of Electronic and Information Engineering, Hong Kong Polytechnic University, Hong Kong. From January to October 2011, he was Senior Scientist in Agency for Science, Technology and Research (A*Star), Singapore. He is currently an Associate Professor in Department of Electrical and Electronic Engineering, The University of Hong Kong, Hong Kong. Dr. Tan was a Visiting Scholar at Grainger Center for Electric Machinery and Electromechanics, University of Illinois at Urbana-Champaign, Champaign, from September to October 2009, and an Invited Academic Visitor of Huazhong University of Science and Technology, Wuhan, China, in December 2011. His research interests are focused in the areas of power electronics and control, LED lightings, smart grids, and clean energy technologies.

Dr. Tan serves extensively as a reviewer for various IEEE/IET transactions and journals on power, electronics, circuits, and control engineering. He is an Associate Editor of the IEEE Transactions on Power Electronics. He is a coauthor of the book Sliding Mode Control of Switching Power Converters: Techniques and Implementation (Boca Raton: CRC, 2011).

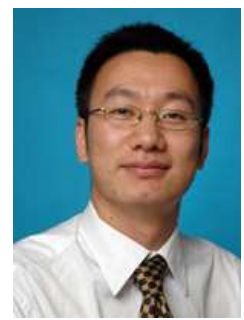

Chuyang Y. Tang received the B.Eng. (Hons.) and M.Eng. degrees in civil engineering from Nanyang Technological University, Singapore, in 2000 and 2001, respectively, the PhD degree from the Environmental Engineering and Science Program at Stanford University in 2006. He was an Assistant Professor (December 2006 - March 2012) and then Associate Professor (March 2012 - July 2013) at the Department of Civil and Environmental Engineering, Nanyang Technological University. Dr. Tang is currently an Associate Professor at the Department of Civil Engineering. He was also the Deputy Director of the Singapore Membrane Technology Centre (November 2012 - July 2013), a Visiting Fellow under the International Desalination Association Fellowship to the Australian Centre of Excellence on Desalination (June - August 2010), a Distinguished Visiting Fellow under the Finland Distinguished Professor Program (December 2010 - December 2013), a Visiting Professor at VTT Technical Research Centre Finland (December 2010 - October 2016), and Sky-Sea Distinguished Visiting Scholar at Dalian University of Technology (August 2016 - present). His main research interests include membrane technology, environmental materials, desalination and clean energy. Dr. Tang is an author of 177 refereed journal papers and an active reviewer of $>30$ academic journals in the domain of water, energy, and materials.

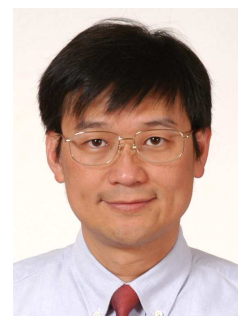

S. Y. (Ron) Hui (M'87-SM'94-F'03) received his BSc (Eng) Hons at the University of Birmingham in 1984 and a D.I.C. and PhD at Imperial College London in 1987. Currently, he is the holder of the Philip Wong Wilson Wong Chair Professorship at the University of Hong Kong. Since July 2010, he has concurrently held a part-time Chair Professorship of Power Electronics at Imperial College London.

He has published over 350 technical papers, including more than 250 refereed journal publications and book chapters. Over 60 of his patents have been adopted by industry. His inventions on wireless power underpin key features of the worlds first wireless charging standard Qi with free-positioning and localized charging. He is an Associate Editor of the IEEE Transactions on Power Electronics and IEEE Transactions on Industrial Electronics, and an Editor of the IEEE Journal of Emerging and Selected Topics in Power Electronics. He is the recipient of the 2010 IEEE Rudolf Chope R\&D Award and the 2010 IET Achievement Medal (The Crompton Medal), and 2015 IEEE William E. Newell Power Electronics Award. He is a Fellow of the Australian Academy of Technological Sciences \& Engineering, and a Fellow of the Royal Academy of Engineering, U.K 